\title{
Trends in Age at Diagnosis of Type 2 Diabetes Among US Adults from 2001 to 2016
}

\author{
Phuc Le, PhD, MPH' , Lu Zhang, MPH', Anita D. Misra-Hebert, MD, MPH', \\ Glen B. Taksler, $P h D^{7}$, William H. Herman, MD, MPH ${ }^{3,4}$, and Michael B. Rothberg, \\ $\mathrm{MD}, \mathrm{MPH}^{\top}$
}

\author{
'Center for Value-based Care Research, Cleveland Clinic, Cleveland, OH, USA; ${ }^{2}$ Department of Management, Policy and Community Health, The \\ University of Texas School of Public Health, Houston, TX, USA; ${ }^{3}$ University of Michigan School of Public Health, Ann Arbor, MI, USA; ${ }^{4}$ University of \\ Michigan Medical School, Ann Arbor, MI, USA \\ J Gen Intern Med 36(4):1144-6 \\ DOI: $10.1007 / \mathrm{s} 11606-020-05767-5$ \\ (c) Society of General Internal Medicine 2020 \\ $<0.05$ was considered significant. We used Stata/MP 14.2, \\ accounting for the complex survey design of NHANES.
}

\section{INTRODUCTION}

The prevalence of diagnosed and undiagnosed diabetes reached $9.4 \%$ of US adults in $2015 .{ }^{1}$ Obesity is a strong risk factor for diabetes and appears to be occurring at younger ages. ${ }^{1}$ Consequently, diabetes may also occur earlier. The American Diabetes Association (ADA) recommends screening for diabetes at 45 years in asymptomatic patients and at any age in overweight or obese adults with risk factors. ${ }^{2}$ Earlier screening might shift the age at diagnosis, but reports of this shift are largely anecdotal. We aimed to describe population-based trends in age at diagnosis of type 2 diabetes (T2D) among US adults.

\section{METHODS}

We conducted a cross-sectional, retrospective analysis using the 2001-2016 National Health and Nutrition Examination Survey (NHANES) data. We included people aged $\geq 18$ years who had an $\mathrm{HbAlC}>6.4 \%$, fasting plasma glucose $>125 \mathrm{mg} /$ $\mathrm{dL}$, or who were previously told they had diabetes. Pregnant women, patients with probable type 1 diabetes (T1D) (aged < 20 years and receiving only insulin), ${ }^{3}$ and patients with missing data were excluded. Age at diagnosis was self-reported. For patients with previously undiagnosed diabetes, we assigned their age at the interview as age at diagnosis, but also conducted sensitivity analysis including only previously diagnosed patients. Duration of diabetes was the difference between age at interview and age at diagnosis. Mean age at diagnosis and duration were estimated for each 2-year period. Trends were assessed using linear regression and mid-points of survey cycles as independent variable. We also calculated the number of patients by age at diagnosis for 2001-2006, 2007-2012, and 2013-2016, respectively. A 2-sided $p$ value

Received February 24, 2020

Accepted March 4, 2020

Published online March 19, 2020

\section{RESULTS}

The sample included 7016 T2D patients (representing 26.2 million US adults), 5308 (75\%) of whom were previously diagnosed. Mean age was 59 years, $52 \%$ were male, and mean BMI was 32.8 (Table 1). Mean age at diagnosis was 50.5 years. Mean duration was 8.4 years. There was no significant change in either mean age or duration from 2001 to 2016 (Fig. 1a). Results were the same when restricted to either previously diagnosed or undiagnosed patients. Compared with 2001-

Table 1 Patient Characteristics of US Adults with Type 2 Diabetes, NHANES 2001-2016

\begin{tabular}{|c|c|c|c|}
\hline & No. & Percentage/mean & $95 \% \mathrm{CI}$ \\
\hline Age (years), mean & 7016 & 59.0 & $\begin{array}{l}58.5- \\
59.5\end{array}$ \\
\hline $\mathrm{HbA1C}(\%)$, mean & 6540 & 7.2 & $7.2-7.3$ \\
\hline \multicolumn{4}{|l|}{ Sex } \\
\hline Female & 3390 & 48 & $47-50$ \\
\hline Male & 3626 & 52 & $50-53$ \\
\hline \multicolumn{4}{|l|}{ Race } \\
\hline Non-Hispanic White & 2545 & 61 & $58-64$ \\
\hline Non-Hispanic Black & 1859 & 16 & $14-18$ \\
\hline Hispanic & 2045 & 15 & $13-18$ \\
\hline Others & 567 & 8 & $7-9$ \\
\hline \multicolumn{4}{|l|}{ BMI } \\
\hline$<25$ & 932 & 13 & $11-14$ \\
\hline $25-29.9$ & 1940 & 27 & $26-29$ \\
\hline $30-34.9$ & 1796 & 28 & $26-29$ \\
\hline$\geq 35$ & 1889 & 32 & $31-34$ \\
\hline \multicolumn{4}{|c|}{ Ratio of family income to poverty } \\
\hline$<1$ & 1547 & 17 & $16-19$ \\
\hline $1-<2$ & 1958 & 26 & $24-27$ \\
\hline $2-<4$ & 1661 & 29 & $27-31$ \\
\hline$\geq 4$ & 1166 & 27 & $25-30$ \\
\hline \multicolumn{4}{|l|}{ Insurance } \\
\hline No insurance & 1011 & 12 & $11-13$ \\
\hline Any private & 3195 & 56 & $54-58$ \\
\hline Public only & 2757 & 32 & $30-33$ \\
\hline \multicolumn{4}{|l|}{ Education } \\
\hline$<$ High school & 2676 & 27 & $25-28$ \\
\hline High school/GED & 1624 & 25 & $23-26$ \\
\hline Some college & 1713 & 30 & $28-32$ \\
\hline $\begin{array}{l}\text { College graduate and } \\
\text { above }\end{array}$ & 986 & 19 & $17-21$ \\
\hline
\end{tabular}

BMI, body mass index; CI, confidence interval; GED, general education diploma; NHANES, National Health and Nutrition Examination Survey 
a) Trends in age at diagnosis

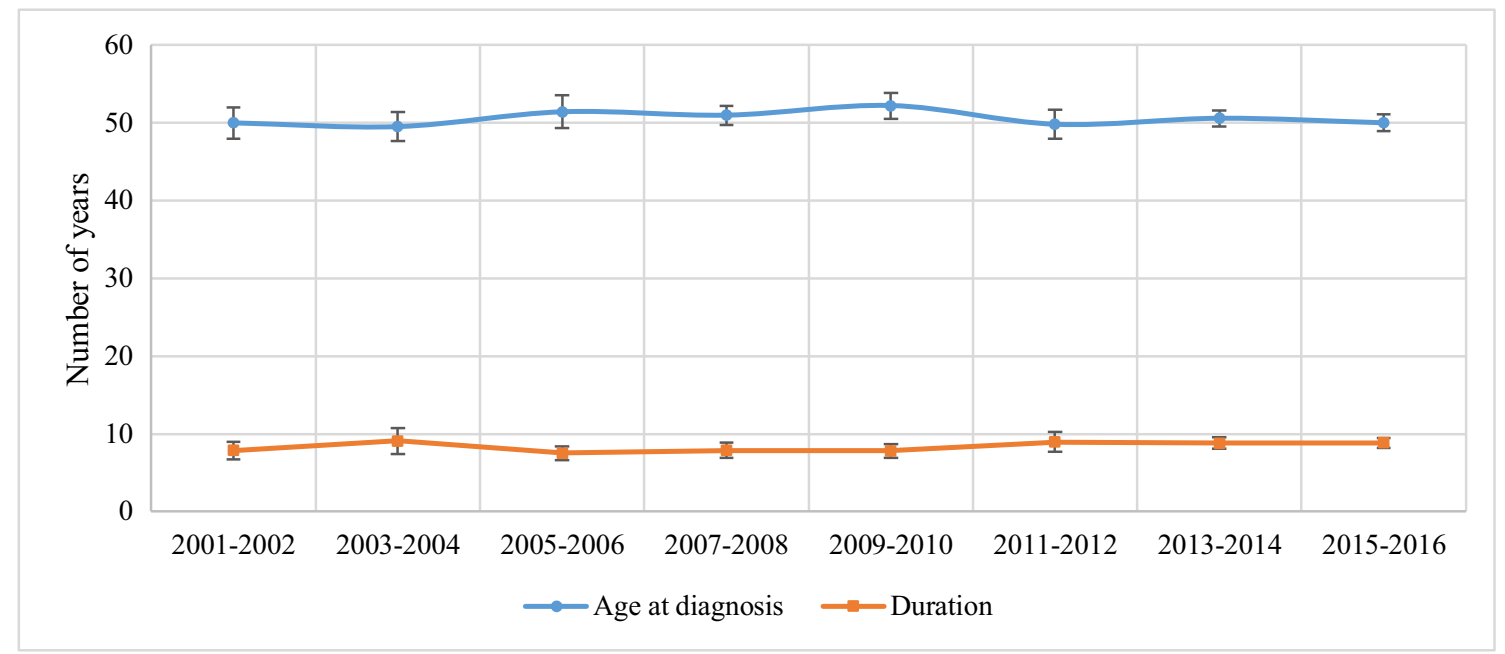

b) Number of US adults with diabetes by age at diagnosis

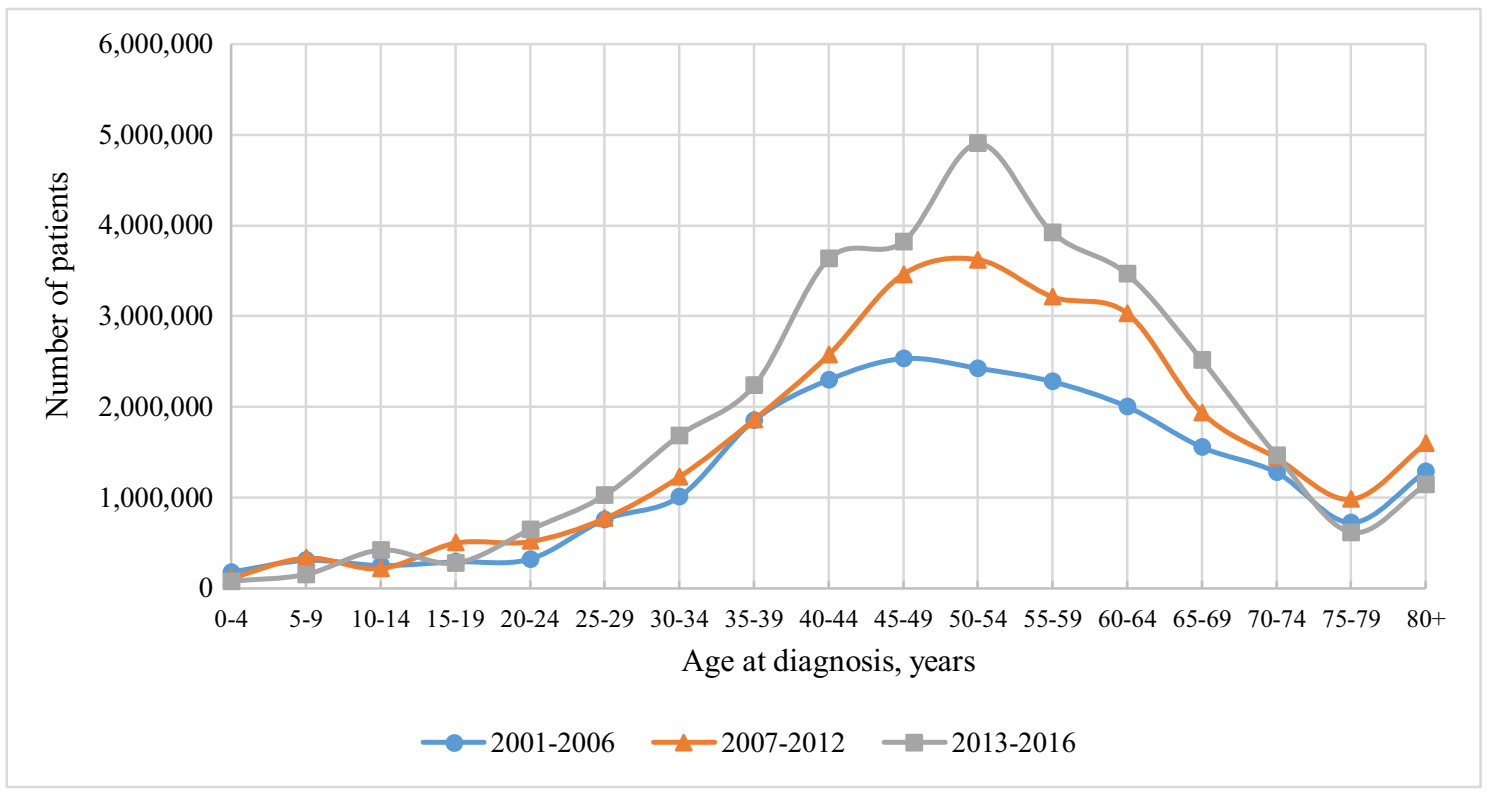

Figure 1 a Trends in mean age at diagnosis and duration of type 2 diabetes in US adults ( $p$ value for trends $>0.05$ ), and $b$ number of US adults with type 2 diabetes by age at diagnosis, 2001-2016. Error bars in a represent $95 \%$ confidence intervals.

2006, the number of patients diagnosed at ages 30-34, 50-54, 60-64, and 70-74 years in 2013-2016 was 1.7, 2.0, 1.7, and 1.1 times higher $(p$ value $<0.001)$, respectively (Fig. $1 b)$.

\section{DISCUSSION}

After decreasing throughout the $1990 \mathrm{~s},{ }^{4}$ the mean age at diagnosis of T2D in the USA appears to have stabilized. Mean age of diagnosis and duration did not change from 2001 to 2016. Overall, there was an increase of 50\% in prevalence of T2D. The number of younger patients - those diagnosed between 30 and 34 years - almost doubled, but so did the number of patients diagnosed between 50 and 54 years, with a much larger absolute increase occurring in the latter group.
Interestingly, there was almost no increase among patients aged $\geq 70$ years. Therefore, although a casual observer might be struck by the increase in diabetes among younger adults, in fact, there were simply more patients with T2D at all ages. Given this finding, the ADA recommendation to begin screening at age 45 appears appropriate.

Our study has limitations. Because age at diagnosis was self-reported, findings were subject to recall bias. Also, since time from diabetes onset to diagnosis is unknown, ${ }^{5}$ we could not confirm when diabetes developed. The NHANES does not distinguish among diabetes types. Since $>95 \%$ of diabetics are type 2, and we excluded probable T1D patients, our estimates generally represent $\mathrm{T} 2 \mathrm{D}$.

In conclusion, we found that age at diagnosis of T2D among US adults did not change over 15 years. Instead, the doubling 
of diabetes prevalence at all ages may have created the appearance of an age shift.

Authors: Phuc Le, $\mathrm{PhD}, M P H^{1}$;

Affiliations: ${ }^{1}$ Center for Value-based Care Research, Cleveland Clinic, Cleveland, OH, USA.

Corresponding Author: Phuc Le, PhD, MPH; Center for Value-based Care Research, Cleveland Clinic, Cleveland, OH, USA (e-mail:lep@ccf.org).

\section{Compliance with Ethical Standards:}

Conflict of Interest: Dr. Herman serves on a Data Safety Monitoring Board for Merck Sharp \& Dohme. Dr. Misra-Hebert receives funding from the Agency for Healthcare Research and Quality grant no. KO8HSO24128 and has received research funding from Novo Nordisk and Merck. All other authors have no conflict of interest.

\section{REFERENCES}

1. Centers for Disease Control and Prevention. National Diabetes Statistics Report: Estimates of Diabetes and Its Burden in the United States, 2017. Atlanta: US Department of Health and Human Services;2017.

2. American Diabetes A. 2. Classification and Diagnosis of Diabetes: Standards of Medical Care in Diabetes-2019. Diabetes Care. 2019;42(Suppl 1):S13-S28.

3. Demmer RT, Zuk AM, Rosenbaum M, Desvarieux M. Prevalence of diagnosed and undiagnosed type 2 diabetes mellitus among US adolescents: results from the continuous NHANES, 1999-2010. American Journal of Epidemiology. 2013;178(7):1106-1113.

4. Koopman RJ, Mainous AG, 3rd, Diaz VA, Geesey ME. Changes in age at diagnosis of type 2 diabetes mellitus in the United States, 1988 to 2000. Ann Fam Med. 2005;3(1):60-63.

5. Porta M, Curletto G, Cipullo D, et al. Estimating the delay between onset and diagnosis of type 2 diabetes from the time course of retinopathy prevalence. Diabetes Care. 2014;37(6):1668-1674.

Publisher's Note: Springer Nature remains neutral with regard to jurisdictional claims in published maps and institutional affiliations. 